\title{
Quantitizing Affective Data as Project Evaluation on the Use of a Mathematics Mobile Game and Intelligent Tutoring System
}

\author{
Eeva NYGREN ${ }^{1}$, A. Seugnet BLIGNAUT ${ }^{2}$, \\ Verona LEENDERTZ2 ${ }^{2}$, Erkki SUTINEN ${ }^{1}$ \\ ${ }^{1}$ Department of Future Technologies, University of Turku, Finland \\ ${ }^{2}$ TELIT-SA, North-West University, South Africa \\ e-mail:eeva.nygren@utu.fi, anitaseugnet@gmail.com,verona.leendertz@nwu.ac.za, \\ erkki.sutinen@utu.fi
}

Received: February 2019

\begin{abstract}
Technology-enhanced learning generally focuses on the cognitive rather than the affective domain of learning. This multi-method evaluation of the INBECOM project (Integrating Behaviourism and Constructivism in Mathematics) was conducted from the point of view of affective learning levels of Krathwohl et al. (1964). The research questions of the study were: (i) to explore the affective learning experiences of the three groups of participants (researchers, teachers and students) during the use of a mobile game UFractions and an intelligent tutoring system ActiveMath to enhance the learning of fractions in mathematics; and (ii) to determine the significance of the relationships among the affective learning experiences of the three groups of participants (researchers, teachers and students) in the INBECOM project.

This research followed a sequential, equal status, multi-mode research design and methodology where the qualitative data were derived from the interviews with researchers, teachers and students, as well as from learning diaries, feelings blogs, and observations (311 documents) across three contexts (South Africa, Finland, and Mozambique). The qualitative data was quantitized (Saldaña, 2009), i.e. analysed deductively in an objective and quantifiable way as instances on an Excel ${ }^{\mathrm{TM}}$ spreadsheet for statistical analyses. All the data was explored from the affective perspective by labelling the feelings participants experienced according to the affective levels of the Krathwohl et al. (1964) framework.

The researchers concluded that: (i) the research participants not only received information, but actively participated in the learning process; responded to what they learned; associated value to their acquired knowledge; organised their values; elaborated on their learning; built abstract knowledge; and adopted a belief system and a personal worldview; and (ii) affirmation of affective learning at all five levels was recognised among the three groups of participants. The study raised a number of issues which could be addressed in future, like how affective levels of learning are intertwined with cognitive levels of learning while learning mathematics in a technology-enhanced learning environment; and how pedagogical models which take into account both cognitive and affective aspects of learning support deep learning.
\end{abstract}

Keywords: Quantitizing, qualitative data, Krathwohl's affective learning levels, mobile games, intelligent tutoring systems, mathematics education. 


\section{Introduction}

Evaluation at the conclusion of international projects is essential. Project evaluation can be executed according to a variety of evaluation techniques which are generally classified into five types: net present value methods, rate of return methods, ratio methods, payback methods, and accounting methods. The net present value method is one of the most popular methods of project evaluation and includes a wide range of techniques (Remer \& Nieto, 1995). Projects that focus on the pedagogical use of learning technologies often encompass multiple teams - especially when they comprise multiple contexts and countries which they relate to. Technology-enhanced learning, game-based learning and gamification have become recognised fields of research (Hamari, Shernoff, Rowe, \& Coller, 2016). Although the positive impact of game-based learning is now widely acknowledged (Hamari, et al., 2016), in depth studies on the use of technology in education are required on how learning with technology impacts on learning (Qian \& Clark, 2016). However, the educational-technology research, in most cases, focuses on the cognitive rather than the affective domain of learning (Ramma, Bholoa, Watts, \& Samy, 2017; Volk, Cotic, Zajc, \& Starcic, 2017) . Studies on game-based learning and gamification mainly describe the learning effects of individual and situational contexts (Nacke \& Deterding, 2017), and little is known about teachers' perceptions of technology-enhanced learning (Domingo \& Garganté, 2016). The successful integration of computer technology into classrooms depends greatly on teachers' acceptance of technology (Admiraal, et al., 2017). Technology integration programmes often fail due to a mismatch between teachers' pedagogical beliefs and technological innovation (Tondeur, Van Braak, Ertmer, \& Ottenbreit-Leftwich, 2016). It is therefore necessary to determine the affective learning experiences of the participating research groups in order to ascertain the success of such an international project and to explore the affective dimension of game-based learning.

This paper provides an evaluation of the INBECOM project (Integrating Behaviourism and Constructivism in Mathematics) in terms of the affective learning experiences according to the Krathwohl, Bloom and Masia (1964) framework. The INBECOM project consisted of five stages, the last of which was the creation of instructional design theory for mathematics teaching and learning advocating a behaviourist-constructivist perspective towards mathematics teaching and learning. All the other levels served as the basis for this last main goal. Classically behaviorist (or objectivist) paradigms has been seen totally opposite to constructivistic learning and instructional design. Instead, INBECOM model uses Cronje's (2006) proposed approach where he seems these two paradigms not diametrically opposite, but instead situated orthogonally so that learning occasion could use both behavioristic and constructivistic elements without the one actually distracting from the other. This article, however, does not focus on exploring integration of these pedagogical approaches into INBECOM model, but concentrates only on the affective learning experiences of the project participants comprising three groups (researchers, teachers and students) who, on different levels, participated in the project on the use of the UFractions mobile game and Cuisenaire rods (mathematics fraction rods which assist students to explore mathematics concepts, especially while 
working with fractions and divisors) across three contexts: South Africa, Finland, and Mozambique. The qualitative data used in evaluation were derived from the interviews with researchers, teachers and students, as well as from learning diaries, feelings blogs, and observations.

Much educational research only focuses on the attaining of cognitive learning outcomes as educators often disregard the affective learning experiences which include inter alia the active participation of the participants; the value participants attach to particular objects or phenomena; or the participants' creating of unique value systems which ultimately control their behaviour (Bolin, Khramtsova, \& Saarnio, 2005). Affective learning experiences are a crucial part of learning which should not only be integrated with the cognitive aspects of learning (Anderson, Krathwohl, \& Bloom, 2001; Bolin, et al., 2005; Littledyke, 2008), but also be applied to the project teams. This paper analysed the affective learning aspects observed during the design, implementation and evaluation of the UFractions mobile game in order to create a technology-enhanced pedagogical model for Mathematics teaching and learning with mathematics rods and a mobile game. By interacting with one another, the project participants learned collectively, developed understandings and interpretations of learning content, accomplished other competences like social and problem solving skills, and also attained certain research goals. The research questions which underpinned this study were: (i) to explore the affective learning experiences of the three groups of participants (teachers, students and researchers) of how the use of the mobile game enhanced the learning of fractions in mathematics according to the five affective levels of Krathwohl, et al. (1964); and (ii) to determine the significance of the relationships among the affective learning experiences of the three groups of participants in the INBECOM project. Four sub-research questions addressed the determining of the significance of the affective relationships.

\section{Literature and Theoretical Background}

From the behaviourist paradigm of learning, Benjamin Bloom and his co-workers classified learning according to three domains: cognitive, psychomotor and affective; each ranging from uncomplicated to complex learning outcomes (Krathwohl, et al., 1964). While Bloom developed the cognitive model which focuses on the acquisition and development of students' intellectual skills which encompass the six well-known levels of knowledge, comprehension, application, analysis, synthesis, and evaluation (Bloom, 1956), Krathwohl, et al. (1964) compiled the affective domain of learning. Although Bloom's cognitive model seems to have become the standard for teachers to identify and classify learning outcomes, as well as to assist during the development of teaching and learning activities (Reigeluth, 1999), all three domains should be considered during the delivery of teaching and learning (Adkins, 2004; Bolin, et al., 2005; Griffith \& Nguyen, 2006). Aspects of the affective domain are often neglected (Grootenboer \& Marshman, 2016), as they are considered to be complex and some teachers assume that students should deal with their affective learning experiences in their own ways (Duncan-Hewitt, Leise, \& Hall, 2005). Moreover, teachers maintain that they do not have time to consider 
the affective domain during preparation of their teaching (Griffith \& Nguyen, 2006). Emphasis is subsequently placed on the assessment of cognitive objectives instead of considering the affective experiences during learning (Bolin, et al., 2005). Attention should be paid to the affective aspects of learning, even if the outcome of the learning is cognitive of nature (Duncan-Hewitt, et al., 2005). The development of affective skills, from the simplest to the most complex, enhances learning across all three domains (Duncan-Hewitt, et al., 2005). The higher levels of the cognitive domain are difficult to achieve if teachers do not develop the complementary skills of the affective domain (Griffith \& Nguyen, 2006). Table 1 outlines the five levels and illustrative verbs of affective learning according to the framework of Krathwohl, et al. (1964), arranged from the least to the most complex learning.

Advancements in psychological theories contributed to the acknowledgement of how the affective domain has been considered and accepted in mathematics education. Initial studies on the affective learning experience in mathematics learning primarily focused on students' attitudes towards mathematics (Ignacio, Nieto, \& Barona, 2006). During preceding decades, research has investigated the beliefs and emotional reactions of mathematics students (Hannula, 2002; Ignacio, et al., 2006; McLeod, 1992). While beliefs and attitudes are generally stable, emotions may change quickly. They may also vary in intensity, in the time that they take to develop as well as in the effect they have on cognitive learning. Emotional reactions can play a significant role in mathematics learning as emotions are directly linked to motivation: either positive (joy, interest), or negative (anger, frustration) emotions develop, depending on the situation (Hannula, 2006). General beliefs about mathematics, or the like or dislike of mathematics, differ from emotional reactions to the solving a difficult mathemat-

Table 1

Five Levels, Definitions and Illustrative Verbs of the Krathwohl, et al. (1964) Framework for Affective Learning

\begin{tabular}{|c|c|c|}
\hline Levels & Definitions & Illustrative Verbs \\
\hline Receive & $\begin{array}{l}\text { Being aware of or attentive to the environment; to be } \\
\text { open to experience; willing to hear and listen; explore } \\
\text { the self and environment; experiencing emotions }\end{array}$ & $\begin{array}{l}\text { To be open to experiences; acknowledge; } \\
\text { ask; attend; identify; discuss; do; feel; } \\
\text { focus; follow; hear; listen; read; retain; } \\
\text { participate }\end{array}$ \\
\hline Respond & $\begin{array}{l}\text { Getting involved with a subject or activity; react to and } \\
\text { participate actively in; engage in life and with others }\end{array}$ & $\begin{array}{l}\text { Assist; become excited; cite; clarify; } \\
\text { contribute; interpret; perform; present; } \\
\text { provide references; question; react; } \\
\text { respond; seek clarification; write }\end{array}$ \\
\hline Value & $\begin{array}{l}\text { Attaching values; expressing personal opinions; building } \\
\text { identity; committing to certain goals, ideas or beliefs; } \\
\text { reflecting; caring for self and others }\end{array}$ & $\begin{array}{l}\text { Argue; challenge; confront; criticise; } \\
\text { debate; justify; persuade; refute }\end{array}$ \\
\hline Organise & $\begin{array}{l}\text { Organising of values into a system; reconciling internal } \\
\text { conflicts; establishing of personal values; choosing with } \\
\text { confidence; realistically envisioning a performance }\end{array}$ & $\begin{array}{l}\text { Arrange; build; compare; contrast; } \\
\text { defend; develop; formulate; modify; } \\
\text { prioritise; reconcile; relate }\end{array}$ \\
\hline Internalise & $\begin{array}{l}\text { Adopting belief systems; adopting a philosophy or } \\
\text { world view }\end{array}$ & Act; display; influence, practise; solve \\
\hline
\end{tabular}


ics problems (McLeod, 1992). While McLeod (1992) indicates that positive attitudes towards mathematics tend to become more negative as students grow older, or when they advance to secondary schools, Ruffell, Mason, and Allen (1998) stipulate that attitudes could change rapidly as "the negative attitude towards mathematics can be a successful defence strategy of a positive self-concept" (Hannula, 2002, p. 8). Grootenboer and Marchman (2016, p. 30) posit that "affect is symbiotically related to learning in mathematics education - students' beliefs, attitudes and emotions influence their learning in mathematics classrooms, and conversely, students develop mathematical beliefs, attitudes and emotions as they are engaging in the activities of the mathematics classrooms."

McLeod (1992) established four axes of beliefs about mathematics learning: mathematics, oneself, mathematics teaching, and the social context in which mathematics is learned (McLeod, 1992). These four axes of learning account for the learning of all three groups of project participants. The students learned about the mathematics, the social context, and themselves; and the teachers and the researchers learned about mathematics teaching, the social context and themselves. Although their learning was not equal, or on the same level, all the project participants shared in the affective learning experiences. Notably, a student's self-concept as a mathematics student is one of the basic descriptors of the affective domain in mathematics (McLeod, 1992). Ignacio et al. (2006) observed that students' beliefs about themselves as mathematics students varied according to gender, but not according to level of schooling. Students who doubt their own abilities, easily give up when faced with difficulties. Their negative beliefs about themselves as mathematics students prevent them from improving their mathematics performance (Chapman, 1988). On the other hand, confidence correlates positively with positive mathematics achievement (Reyes, 1984). The longitudinal study of Hannula, Bofah, Tuohilampi, and Metsämuuronen (2014) shows that mathematical self-efficacy and achievement are reciprocally linked, but the direction and clarity of connections between affective factors and mathematical achievement are complex and indirect. McLeod, Metzger, and Craviotto (1989) observed that although the emotional reactions associated with solving problems were the same for expert and novice students, expert problem solvers were able to control their emotions better than the novices, as they remained flexible and also tried out alternative strategies.

In traditional learning environments, teachers are responsible for adopting both cognitive and affective strategies during teaching and learning. Technology-enhanced learning in classrooms may reduce human interaction, especially if students are immersed in learning materials that do not involve social interaction like drill-and-practice tasks and tutoring systems where the pupil interacts only with the computer. However, technology can even help students to find an interaction dimension, for example, in a situation where the student has social disabilities. Therefore it is crucial to ensure that the use of technology is responsibly integrated into teaching and learning in order to manage the affective aspects of learning (Lehman, D’Mello, \& Graesser, 2012; McLeod, 1992).

Lehman, et al. (2012) define academic emotions and learning-centred emotions according to the variations in the duration of learning. Affective emotions consider par- 
ticipants' experiences during a wide range of activities (e.g. during a project). However, learning-centred emotions can also be captured during shorter learning sessions, like playing a serious game for one hour. Calvo and D'Mello (2011) assert that in shorter learning sessions, students' emotions could include boredom, engagement (flow), confusion, frustration, anxiety, curiosity, delight, and surprise. These authors compiled a model to explain the dynamics of affective experiences which emerged during learning activities (D’Mello \& Graesser, 2011). The model indicates that students do not randomly move from one emotion to another. Moreover, the model presumes that students in a state of engagement (flow) experience cognitive disequilibrium and confusion when they face contradictions or obstacles to goals. Students will return to the engaged (flow) state if they are able to solve a problem or overcome an obstacle (Kiili \& Pertttula, 2012). Several studies show that using game-based learning and gamification contexts provoke engagement and flow in students (Barzilai \& Blau, 2014; Hamari, et al., 2016). However, if students fail to repair equilibrium, their frustration will increase and they could become bored. Baker, D’Mello, Rodrigo, and Graesser (2010) examine three different computer-based learning environments and they provide evidence that boredom persists across different learning environments and is associated with poor learning and problematic behaviour. Frustration is, to a lesser extent, associated with low achievement.

\section{Project Information}

Serious games (games for learning) contribute to effective and meaningful learning (Alessi \& Trollip, 2001; Kiili \& Pertttula, 2012; Rieber, 2001). These games provide engaging flow experiences to students, often causing them to lose track of time and space (Rieber, 2001). Serious games also enhance intrinsic motivation and contribute to enriched learning experiences (Alessi \& Trollip, 2001). The INBECOM model encompassed two components: a constructivist mobile game, UFractions and an intelligent tutoring system, ActiveMath. UFractions is a story-based game, which was designed and developed in South-Africa (Nygren, Blignaut, Els, Laine, \& Sutinen, 2009) and discloses Mother Leopard and her newborn cub, Senatla. Game players solve fractions by using Cuisenaire fraction rods in order to help the leopards to meet the challenges of finding food, learning how to hunt, and veering off enemies. The UFractions mobile game comprises different levels, each with increased difficulty levels of fraction theory. Through interaction with the leopards, the player accumulates points and contributes to the guest book. ActiveMath forms an integral part of the INBECOM model. The ActiveMath system guides students to self-regulated learning in order to develop individual knowledge, cultivate personal interests and establish learning goals. The ActiveMath system can be adapted to different pedagogical strategies and content. Students participate in interactive exercises and receive immediate feedback. The system uses artificial intelligence to adapt courses and student modelling. Intelligent tutoring systems (ITSs) are computer software designed to emulate a human tutor's behaviour and guidance, and have been developed and researched since 
the 1970s (Nwana, 1990). Various studies indicate that ITSs are powerful tools for mathematics teaching and learning (Özyurt, Özyurt, Baki, \& Güvenb, 2013; Verner, Aroshas, \& Berman, 2008).

The researchers conducted the INBECOM project according to five stages: (i) planning an educational model; (ii) development, experimentation and evaluation of the UFractions mobile game; (iii) content and translations, experimentation and evaluation of the ActiveMath intelligent tutoring system; (iv) presenting a fraction course according to the INBECOM model in Finland; and (v) a theory generating the INBECOM model.

Fig. 1 illustrates the research design and methodology as well as the outline of the five levels of the INBECOM model.

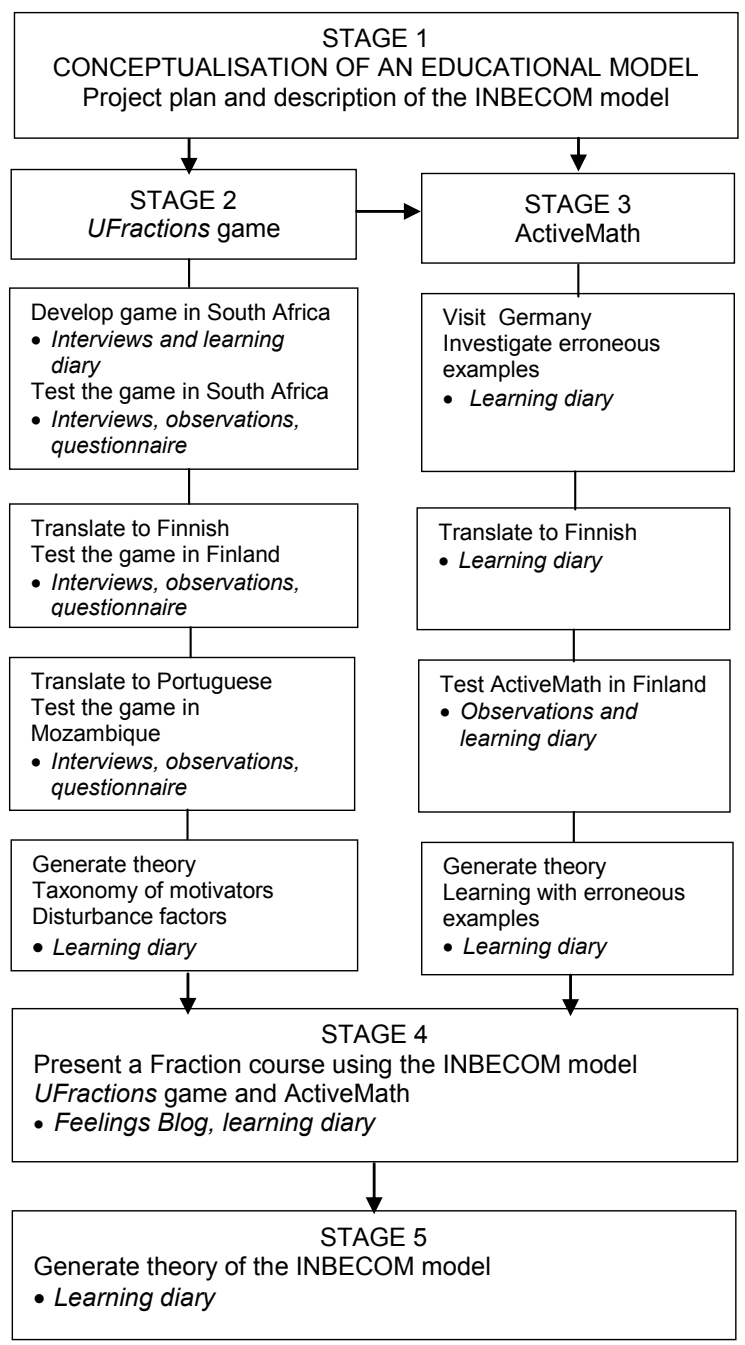

Fig. 1. Five Stage Design of the INBECOM Model. 
The project commenced with the development of a teaching and learning model for mathematics teaching using technology-enhanced learning tools as support mechanism. The project comprised multiple aims: (i) to generate an instructional design theory for mathematics teaching and learning which advocates an innovative behaviourist-constructivist perspective towards mathematics teaching and learning; (ii) to create a story-based context-aware mobile game that uses mathematical manipulatives; (iii) to examine how the use of various learning materials in computer-based systems contributes towards the development of cognition of mathematical concepts; (iv) to explore the affective learning experiences of the project participants; and (v) to determine the significance of the relationship among the affective levels of the three groups of participants in the INBECOM project.

As the understanding of fractions is generally considered to be one of the common areas of misconception throughout mathematics education, a mobile game was developed to address this content area (Nabors, 2003). The INBECOM pedagogical design model for mathematics teaching and learning is based on the suggestion that behaviouristic (or objectivistic) and constructivistic approaches does not exculude each other in instructional design, but instead an effective learning event could use complementary elements from both paradigms (Cronje, 2006; Elander \& Cronje, 2016). Accordingly, learning during the project was organised according to the INBECOM model and divided into three activities comprising both behaviouristic and constructivistic elements (Table 2). The five stages of the INBECOM model are discussed according to Fig. 1.

\section{Stage 1:}

Conceptualisation of an educational model, establishing a project plan and developing a description of the INBECOM model.

\section{Stage 2:}

Developing the UFractions mobile game; testing the UFractions mobile game and generating the theory. The first author visited the North-West University in South Africa for three months in 2009 and created the game with the help of South African experts. Local teachers assisted the researchers to define a suitable level of mathematics for the game (Turtiainen, Blignaut, Els, Laine, \& Sutinen, 2009). UFractions was test-

Three Elements of the INBECOM Model

\begin{tabular}{ll}
\hline Element & Description \\
\hline Game element & $\begin{array}{l}\text { Students gameplay a problem-based mobile game (UFractions) based } \\
\text { on fractions as a mathematical concept }\end{array}$ \\
Teacher involvement & $\begin{array}{l}\text { Teacher interacts with students through explanation, visualising and } \\
\text { discussion }\end{array}$ \\
Intelligent tutoring system & $\begin{array}{l}\text { Students learn concepts of fractions through the tutoring system } \\
\text { (ActiveMath). Activities comprise theory and practical exercises }\end{array}$ \\
\hline
\end{tabular}


ed in three biographical contexts: South Africa, Finland and Mozambique. The game content was translated from the original English to Finnish and Portuguese in order to accommodate research participants in each target context. No other changes were made to the game. During data collection, the participants completed a biographical information section of the questionnaire and they played the game for about 30-45 minutes. During gameplay, the researchers observed the gameplay and the teachers provided game interface, as well as content specific guidance to the participants when required. Upon finishing the game, the participants completed the second part of the questionnaire. Afterwards, the researchers interviewed three to five volunteer participants from each evaluation group, as well as their teacher. The researchers analysed the gameplay experiences of all three testing contexts (Laine \& Nygren, 2014; Laine, et al., 2011) and developed a taxonomy of play motivations for the UFractions mobile game which included altruism, challenge, cognitive restlessness, curiosity, fantasy, relations, and technology (Nygren, Sutinen, Blignaut, Laine, \& Els, 2012). Additionally, the researchers analysed the connections between motivators and disturbance factors.

\section{Stage 3:}

Consideration of ActiveMath intelligent tutoring system use for fractions teaching. The first author visited the University of Saarbrücken in Germany, investigated erroneous examples with an adaptive error-detection and error-correction help, translated the fraction content to Finnish, and incorporated it in the ActiveMath system (Tsovaltzi, et al., 2010). She applied the tutoring system in Finland with 36 grades 9 and 10 students. The design included a pre-questionnaire, a pre-test, a familiarisation, an intervention, a posttest and a post-questionnaire. The first author generated theory to determine whether the use of erroneous examples in ActiveMaths contributed towards the development of the cognition of fractions in mathematics teaching and learning.

\section{Stage 4:}

The first researcher presented a course on fractions that was organised according to the INBECOM model at the Folk High School in Kitee, Finland. Twenty-one students participated in the course. The course lasted one month and included eleven contact sessions. The instruction of the students' component was increased to thirty minute sessions instead of fifteen minutes, which included the game elements as well as the ActiveMath approach to teaching and learning. The students played the UFractions mobile game and designed their own mobile game stories and fraction problems. The students wrote self-reflections on their experiences and feelings in the How-am-Ifeeling? blog with the aim of achieving the learning objectives and affective learning experiences. In a learning diary, the first author captured her reflections on her teaching experiences.

\section{Stage 5:}

Theory generation of the INBECOM model. This article, however, focuses only on the affective learning experiences of the project participants in the INBECOM project and does not address the theory generation aspects of the INBECOM model. 


\section{Research Methods}

\subsection{Research Design and Methodology}

This research followed a sequential, equal status, multi-mode research design and methodology (Leech \& Onwuegbuzie, 2007) where the qualitative data were derived from the interviews with researchers, teachers and students, as well as from learning diaries, feelings blogs, and observations. The data documents listed in Table 3 were captured as primary documents in Atlas.ti ${ }^{\mathrm{TM}}$ version 7 and analysed deductively according to the affective levels of the Krathwohl et al. (1964) framework. After checking the analysis for reliability of coding, the researchers quantitized (Saldaña, 2009) the qualitative data as instances on an Excel ${ }^{\mathrm{TM}}$ spreadsheet for statistical analyses. Statistical Consultation Services of the North-West University, South Africa, captured the data in SPSS ${ }^{\mathrm{TM}}$ and performed the following statistical procedures in order to determine the relationships between affective levels qualitatively observed during the INBECOM project as pertinent questions relating to the current study: (i) grouping of the 3405 instances with Mauchly's test of sphericity (ANOVA) to determine the variance-covariance matrix in repeated measures analysis of variance; (ii) Friedman's ANOVA (two-way analysis to determine if mean ranks of the three related groups differ significantly) and Kendall's coefficient of concordance (measure the partial association of ordinal variables in

Table 3

Primary Documents and Participants

\begin{tabular}{lll}
\hline Participants & Data Sources as Primary Documents & Number of participants \\
\hline Researcher 1 & Project plan & 1 researcher \\
Researcher 1 & Description of the INBECOM model & 1 researcher \\
Researcher 10 & Interview of cultural expert & 1 researcher \\
Researcher 9 & Interview of a professor & 1 researcher \\
SA students & Interview of students after game tests in SA & 20 students \\
SA teachers & Interview of teachers during UFractions game tests & 5 teachers \\
South African teachers & Questionnaire to teachers, SA UFractions tests & 5 teachers \\
Finnish students & Questionnaire, UFractions tests & 78 students \\
SA students & Questionnaire, UFractions tests & 116 students \\
SA researchers & Questionnaire & 7 researchers \\
Finnish teachers & Interview of teachers during UFractions game tests & 5 teachers \\
Finnish students & Interview of students during UFractions game tests & 26 students \\
Mozambican students & Questionnaire to players, Mozambique UFractions tests & 69 students \\
Mozambican teachers & Questionnaire & 2 teachers \\
Mozambican teacher & Interview of teachers during UFractions game tests & 2 teachers \\
Finnish students & How-I-am-feeling?-blog during mathematics course & 21 students \\
Researcher 1 & Experiment notes of ActiveMath tests & 1 researcher \\
Researcher 1 & Learning experiences as learning diary during the project & 1 researcher \\
\hline
\end{tabular}


which one or more other ordinal variables could be partially controlled); (iii) general linear and mixed models which contain both within-subjects and between-subjects elements; and (iv) effect sizes which indicate the relationship between variables (Cramer \& Howitt, 2004).

\subsection{Data Collection Strategies}

Although the INBECOM project ran over a period of multiple years, data collection took place from 2007-2014 as snap-shots of the situation at that time and place. The research participants comprised the researchers, teachers, and students from three countries: South Africa, Finland, and Mozambique. Table 3 lists the primary documents used and the relating participants.

The documents from the researchers, teachers and students tallied 311: data from (i) ten researchers (South Africa and Finland) who participated in the design, development, implementation and evaluation; (ii) twelve teachers (South Africa, Finland, and Mozambique) who contributed to the evaluation of the project; (iii) one Kid's Club teacher and eleven secondary school teachers from Finland who implemented the project; and (iv) 289 students who shared in the implementation and evaluation (118 from South Africa, 103 from Finland, and 68 from Mozambique).

\section{Addressing the Research Questions Relating to the Qualitative and Quantitative Components of the Analysis}

\subsection{Findings of the Qualitative Data Analysis}

To address the first research question - to explore the affective learning experiences of the three groups of participants on how the use of the mobile game enhances learning of fractions in mathematics - the 311 data documents (Table 3) were formatted for consistency and easy reading, and were assigned to a hermeneutic unit in Altas.ti ${ }^{\mathrm{TM}}$ for deductive analysis according to codes in order to capture the detail of the five levels of the affective learning experiences (Krathwohl, et al., 1964). The authors systematically made sense of the data through selecting, categorising, comparing, synthesising and interpreting the data according to the constant comparative method of Boeije (2002), where each code's occurrence was tested across all the documents (McMillan \& Schumacher, 2001). Affective learning codes were noted across all the five levels (receive, respond, value, organise, and internalise) of the participating research groups (students, teachers and researchers) involved in the study. The illustrative verbs of the Krathwohl framework (Table 1) were employed as codes during the deductive coding and analysis of the data. Table 4 lists the structure of the qualitative analysis according to the themes, and code density. 
Table 4

The Themes and Code Density of the Qualitative Analysis

\begin{tabular}{|c|c|c|c|c|c|c|c|c|c|}
\hline \multicolumn{2}{|l|}{$\begin{array}{l}\text { Level } 1 \\
\text { Receive } \\
(15 \text { codes })\end{array}$} & \multicolumn{2}{|l|}{$\begin{array}{l}\text { Level } 2 \\
\text { Respond } \\
(14 \text { codes })\end{array}$} & \multicolumn{2}{|l|}{$\begin{array}{l}\text { Level } 3 \\
\text { Value } \\
\text { ( } 8 \text { Codes })\end{array}$} & \multicolumn{2}{|l|}{$\begin{array}{l}\text { Level } 4 \\
\text { Organise } \\
(11 \text { codes })\end{array}$} & \multicolumn{2}{|l|}{$\begin{array}{l}\text { Level } 5 \\
\text { Internalise } \\
\text { ( } 5 \text { codes })\end{array}$} \\
\hline Be open to experience & 187 & Assist & 66 & Justify & 227 & Arrange & 2 & Act & 4 \\
\hline Acknowledge & 214 & Become exited & 58 & Argue & 145 & Build & 49 & Display & 14 \\
\hline Ask & 12 & Cite & 0 & Challenge & 186 & Compare & 32 & Influence & 31 \\
\hline Attend & 48 & Clarify & 69 & Confront & 6 & Contrast & 15 & Practice & 29 \\
\hline Identify & 49 & Contribute & 11 & Criticise & 123 & Defend & 21 & Solve & 74 \\
\hline Discuss & 29 & Interpret & 8 & Debate & 19 & Develop & 202 & & \\
\hline Do & 180 & Perform & 128 & Persuade & 2 & Formulate & 3 & & \\
\hline Feel & 509 & Present & 5 & Refute & 7 & Modify & 15 & & \\
\hline Focus & 71 & Provide references & 191 & & & Prioritise & 12 & & \\
\hline Follow & 14 & Question & 7 & & & Reconcile & 17 & & \\
\hline Hear & 4 & React & 21 & & & Relate & 11 & & \\
\hline Listen & 29 & Respond & 88 & & & & & & \\
\hline Read & 19 & Seek clarification & 16 & & & & & & \\
\hline Retain & 17 & Write & 17 & & & & & & \\
\hline Participate & 88 & & & & & & & & \\
\hline Total: & 1470 & & 685 & & 715 & & 379 & & 152 \\
\hline$N=3405$ & & & & & & & & & \\
\hline
\end{tabular}

\subsubsection{Receive}

The highest density of codes was related to the lowest level of Bloom's taxonomy of affective learning, namely the receive stage. In general, the students were open to the new learning experiences, asked for advice, listened to their teachers and peers and discussed.

- "I enjoy working with numbers, I like maths very much and I enjoy it" (South African student)

- "If we don't understand we go and ask the teacher" (South African student)

- "I listened well at the school.." (Finnish student)

Considering the playing experience with UFractions, students acknowledged their feelings when they played the game, mentioned the attributes of the game which they liked and which they learnt from and mentioned concentration on the game play.

- "I liked that we were able to the mother to hunt for the cub and we were able to use the rods." (South African student)

- "I enjoyed playing mobile phone" (South African student)

- "The game catches the attention of the players." (South African student)

- "It got me more interest in the fractions." (South African student)

- "There were good instructions/advice, that were easy to follow and decide the answer" (South African student) 
- "Well, repeating these things was a good thing" (Finnish student)

Feelings were described in many comments related to all interventions during the project. Emotions and feelings are certainly essential part in human rational thinking mechanism and emotions affect our behavior at home, school and work as well as learning (Damasio, 2008; Goleman, 1998; Martınez-Miranda \& Aldea, 2005). The feelings can be described by eclectic words, but research has determined eight basic emotions: anger, fear, happiness, sadness, love, surprise, disgust, and shame (Goleman, 1998).

- "Everything in the course was nice, nothing was bad" (Finnish student)

- "Today was a good day, funny exercises at the maths lessons" (Finnish student)

- "Hunger for knowledge, eager" (South African student)

Teachers comments' related to the receiving stage of Bloom's taxonomy were slightly different, and related mostly to the UFractions game since teachers' data contained mostly playing experiences. Teachers acknowledged the good sides of the game, spoke about students' attendance during the game play, as well as concentration and focus

- "What I liked about it, that they were all active." (South African teacher)

- "The game brought the students into the activity and that's the main thing" (South African teacher)

- "It attracts the interest" (Mozambiquen teacher)

- "Game would involve everybody. It's like computive learning." (South African teacher)"

- "Yes, you see... that boy sitting there is one of the weak ones. He was very active." (South African teacher)

- "So it is not just thinking about the fraction in your mind, you are actually doing it with your hands. Hands-on experience." (South African teacher)

Researchers' data included more diverse data than teachers' data and is related to all intervention elements. They focused on various matters, thought that asking, hearing, reading, following and attending is an important thing related to learning, likewise discussion with other researchers or teachers

- "There were intriguing lectures during the day" (Finnish researcher)

- "I was able to ask for advice" (Finnish researcher)

- "I will go with them to a local school next day and follow how they are doing empirical tests of ActiveMath software" (Finnish researcher)

- "I also read some theory of constructivism and behaviorism." (Finnish researcher)

- "We had a discussion about the challenges and opportunities of multidisciplinary research approaches" (Finnish researcher)

Researchers described how they did different kinds of activities and how they felt

- "We tested Ufractions game in 5 different schools." (Finnish researcher)

- "It was quite a thrilling situation to present my own work in front of experts." (Finnish researcher) 


\subsubsection{Respond}

Regarding the second stage, responding, the students became animated, interpreted and gave references. Students contributed to the UFractions game play by giving many ideas how to develop it. Compared to the comments at receive stage, the students were more reactive and showed more active participation.

- "This game of course. It was nice to make this game by yourself, and of course to play!!" (Finnish student)

- "It's like when something gives you the strength to go on, like you don't get... you always get the positive way." (South African student)

- "Well, like... especially the questions... the questions and the rods. Yes. I got motivated by the rods. Because every time you had to change the rod. If you take the green you had to chance from the light red and get green and work as much fast as you can." (South African student) )

- "If we don't know the centimeter, then we used the white block and then counted how long will the block be." (South African student)

Performing was mentioned more often in students' remarks than in teachers' and researchers' comments. Assisting team members was often commented positively.

- "I did want to get highest points but unfortunately I didn't." (South African student)

- "I think that the teacher expects me to perform with good marks and good behaviour" (South African student)

- "when we do something different we can teach others."(Finnish student)

- "The good sides was the digital that you can play in groups by only using one mobile phone. That was good about it." (South African student)

The teachers' comments related to respond stage display how students got animated of game play. Teachers clarify and interpret issues, as well as give examples.

- "It was motivating, you saw they didn't want to stop playing." (South African teacher)

- "Perhaps excitement is a little bit strong word to use but certainly it invoked interest and commitment" (Mozambiquan teacher)

- "they were doing with a possessed enthusiasm" (Finnish teacher)

- "He could make the connection between 6 over 10 is same actually than 3 over 5." (South African teacher)

Researchers appreciated assisting each other. Considering research they soughed clarification, contributed, interpreted and gave references and showed interested in research outcomes.

- "it is really valuable to get support from the people working in the same area" (Finnish researcher)

- "This enables UFractions to adapt to both context and player type." (Finnish researcher)

- "We have analyzed the results and put them together" (Finnish researcher) 
- "You know there are certain qualities that people are born with and grown in particular place. You know, there are things that you are interested in, maybe of the influence of the community and the parents, that is what is happening." (South African researcher)

Researchers showed active participation also by making questions, reacting and responding.

- "How am I going to research and evaluate motivation?" (Finnish researcher)

- "Listeners were asking lots of questions" (Finnish researcher)

\subsubsection{Value}

Regarding value stage, students saw worth in using ICT and playing games. They accepted or committed stances of action by making justifications and arguing. Students expressed their personal opinions also by noticing challenges and criticizing.

- "I could tell you guys, just continue doing those games. They're giving us more knowledge, like they're giving us a clue about maths, many learners don't know fractions. So they were giving us an idea. Then, continue and I wish you all the luck." (South African student)

- "You could put there more chapters because there are only four chapters there." (South African student)

- "I found it really difficult to make an own story to the own game!" (Finnish student)

- "It was difficult to calculate the amount of time that the mother spent outside home" (Mozanbiquan student)

Teachers attached values by advocating their opinions. They argued the effects of the game. Moreover, they found challenges, dabated and criticized.

- "At least when I got to the stage where we started to count, where there was two wholes and one-thirds and these answers, so at that point it could be really good" (Finnish teacher)

- "It really increases the effectiviness." (South African teacher)

- "It enhances the learning process. It makes the learning process much easier." (South African teacher)

- "The problem is coming from the primary schools, for example multiplication they do not know. Very basic things they don't know. So we are having the problems. When you look at these disadvantage students, coming walking far to the school, they don't have proper homes... we have problems they don't do their homework." (South African teacher)

- "But if they ever did then that game would cease to be of interest because you know who is going to win from the beginning, therefore why play? There has to be an element of uncertainty before a game becomes popular." (Mozambiquan teacher)

- "In the screen there is so small text that it is really difficult to see it" (Finnish teacher) 
Researchers shared their perspectives by justifying, arguing and debating. Furthermore, they found challenges in the use of ICT as well as making research.

- "Every single person should have basic maths skills as this would enhance their cognitive abilities + function abilities" (South African researcher)

- "The economic realities of the South African education system ascertain that it is a long way from the situation where mobile games will become commonplace in South African classrooms." (Finnish researcher)

- "it is not worth of just playing games -it is about playing games for learning. You really have to think about pedagogy while designing games!" (Finnish researcher)

- "The exercises were too difficult for them, they were really slow with computers and immigrants did not understand the language well enough" (Finnish researcher)

\subsubsection{Organize}

Related to organize stage, students built knowledge and established relationships by making comparisons.

- "I got to understand if 3/4 then you know that the blue rod is smaller, and then you have to add one light blue for you to get a right fraction. So they were very useful." (South African student)

- "Its more nice to learn maths by playing a game unlike learning it in class" (South African student)

- "it might be little bit more interesting with the phone than by writing" (Finnish student)

Students also defended their ideas.

- INTERVIEWER: How did the rods help you to solve problems?

- INTERVIEWEE: I didn't have to think and like... in my brains something, I could just have the rods and like do it in front of my eyes. It was like the evidence was there. So it was easy to get the answer." (South African student)

Students participated in the game development and had also wider perspective of technology use in the schools.

- "I said on my answer sheet that you could have maybe have more interaction, like you could guide the leopard on where to go and then if you bump in to a problem, only once you have answered correctly you can press key. And you can also put more control what will happen next." (South African student)

- "I just wish we could see more of this in schools: School work (mathematics) + technology = fun" (South African student)

Teachers orzanized or conceptualized values by making comparisons and developing ideas related to the game play and use of ICT in the schools.

- "They could handle the Cuisenaires and I think that really added to them crasping the concept of fractions even to a greater degree." (South African teacher) 
- "I have came from the primary school where we played a lot. In practise we learned multiplications with games." (Finnish teacher)

- "I think you probably would need a bit of in-service training for teachers." (Mozambiquan teacher)

Researchers compared and contrasted things. Their comments demonstrate clearly how organization stage is about adapting new information into existing schema. They determined how the new information makes sense by theorizing issues.

- "The taxonomy of motivations offers a tool for a user adaptation of UFractions, namely establishing player types based on motivations" (Finnish researcher)

- "One thing with our people, there is something like motto, the motto is "build on the indigenous". It means what you have at the beginning is going to be at the bottom and everything else that you learn about or you get expose to will be put on top of it. So that you remain yourself, but also diversify and open up. It does not mean traditional people cannot accept modern things. I think everybody in South Africa these days is accepting the technological boost." (South African researcher)

\subsubsection{Internalize}

Considering the most complex stage, internalization, students made the new information part of their schema by recognizing influences of learning mathematics and playing UFractions game.

- "without maths there's NO future it's one thing I cannot live without" (South African student)

- "I can start my own small business if I know maths" (South African student)

- "You really learn a lot and in future it helps you" (South African student)

- "Maths is your future because you can't find a work without Maths, everywhere you go you hear about Maths" (South African student)

Students exhibited new behavior, attitude or belief. In addition, they practiced and solved issues.

- "you don't know something, go to extend, go to a point that...like go into research and get to understand the thing is doing clearly. So I prefer like, if you don't know something go for research and then if you still don't know the answer. ask someone who knows it. Then you can get the bigger picture what you are doing." (South African student)

- "Nothing! If I don't know something, I will practice at home." (Finnish student)

Teachers perceived the influence of technology and gave self-reliantly comments on how the game could be used and developed further.

- "I think it makes the school attractive for the prospective parents to know that they've got these kinds of resources to challenge the children." (Mozambiquan teacher)

- "I think it's just beneficial for the children's learning for this particular school. You know we don't have a special needs department where children who struggle 
are looked after. I think that could be a way to benefit a child that does struggle." (Mozambiquan teacher)

- "It will be interesting to develop games in other topics in Mathematics." (South African teacher)

Regarding internalizing stage, researchers' comments that show adopting belief system and philosophy are related to identifying influences of actions. Researchers also give evidence of behaving sonsitently with their own value set by solving different dilemmas and creating new theory related to the use of ICT.

- "I feel that it has widened my viewpoint of the whole life, not just teaching and learning." (Finnish researcher)

- "What do learners experience new game in terms of motivation and effective learning?" (Finnish researcher)

\subsection{Results of the Quantitative Analysis}

To determine the significance of the relationships among the affective learning experiences of the three groups of participants in the INBECOM project, the Statistical Services of the North-West University captured the survey data in SPSS and performed various listed statistical procedures. To establish the distribution of the scores of variables, the data were presented as a Box-and-Whisker plot that represented the distribution of scores of variables (Fig. 2). The horizontal scales indicated the value of the scores and the vertical lines marked the highest and lowest values in the data (Cramer \& Howitt, 2004). It also graphically illustrated the distribution of the qualitatively observed affective levels, con-

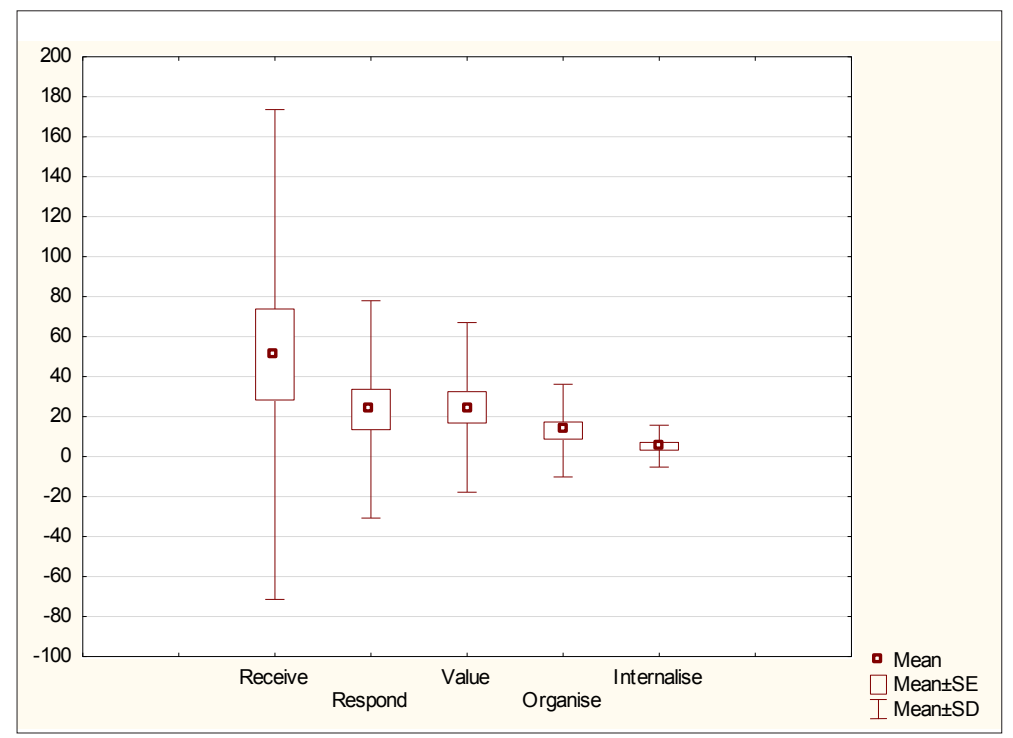

Fig. 2. Box-and-Whisker Plot of the Quantitized Data. 
Table 5

Descriptive Statistics of the Five Affective Levels as Represented in the Box-and-Whisker Plot

\begin{tabular}{llrrr}
\hline Variable & Average rank & Sum of ranks & Mean & Standard deviation \\
\hline Receive & 4.017 & 116.500 & 51.068 & 122.494 \\
Respond & 3.069 & 89.000 & 23.620 & 54.347 \\
Value & 3.810 & 110.500 & 24.655 & 42.401 \\
Organise & 2.637 & 76.500 & 13.069 & 23.162 \\
Internalise & 1.466 & 42.500 & 5.241 & 10.453 \\
\hline
\end{tabular}

firming the hierarchical nature of the levels (Krathwohl, et al., 1964), and substantiating that engagement originated from the less complex affective level. This Box-and-Whisker plot substantiates the values of the quantitized data indicated in Table 4.

The affective levels organise and internalise were statistically less significant in the whole group than receive, as can be seen from the means and standard deviation in Table 5.

\subsubsection{Relationship Among the Five Affective Levels}

In order to determine the statistical relationships among the five affective levels - research question 2 - the researchers performed an ANOVA, Mauchly's test of sphericity with a $\mathrm{p}=0.000$ indicated significant differences between the different affective levels. The Greenhouse-Geisser values $(f=105.434, p=0.000)$ indicated that there were significant differences between at least two of the affective levels (Cramer \& Howitt, 2004) (Table 6). Receive showed practically significant relationships with respond $(d=0.54)$, value $(d=0.53)$, organise $(d=0.76)$, and internalise $(d=0.92)$.

Participants from the three groups all engaged in learning aspects in the project, but not in the same manner and on different levels. The project evaluation data indicated that the relationship among the five affective level constructs denoted that, in order for participants to learn effectively, they in the first place have to be open to the learning experience in order to receive the message(s) related to their specific learning area. Table 6 illustrates a significant relationship between receive and all the other four affective levels.

Table 6

Effect Sizes of Relationship Among the Five Affective Levels

\begin{tabular}{lllll}
\hline & Respond & Value & Organise & Internalise \\
\hline Receive & $0.54^{\mathrm{a}}$ & $0.53^{\mathrm{a}}$ & $0.76^{\mathrm{a}}$ & $0.92^{\mathrm{a}}$ \\
Respond & - & - & - & - \\
Value & 0.01 & - & 0.22 & 0.37 \\
Organise & - & 0.23 & - & 0.61 \\
Internalise & - & $0.39^{\mathrm{b}}$ & - & - \\
\hline
\end{tabular}

${ }^{\text {a }}$ Medium to large effect (practical significance)

${ }^{\mathrm{b}}$ Medium effect (tends toward practical significance) 
This signifies that before participants can respond, value, organise or internalise, they must be open to various learning experiences, focus on the learning at hand, discuss the learning with their fellow research participants, retain the learning content, identify with the concepts of the learning, and participate in the learning activities. Fig. 2 illustrates the hierarchical nature of the taxonomy of affective learning experiences (Krathwohl, et al., 1964) of the project participants.

\subsubsection{Relationships Among the Three Groups of Participants}

To determine the statistically significant relationships among the three groups of participants (students, teachers, and researchers) during the evaluation of the affective levels, the researchers performed comparisons among the means of the five affective levels. Table 7 shows that all the relationships were statistically significant $(p=0.000)$. Table 8 lists the effect sizes of the relationships among the three groups for the five affective levels which indicate a practically significant relationship for receive between teachers and students $(\mathrm{d}=0.43)$; for value between teachers and students $(\mathrm{d}=0.50)$; and for value between researchers and teachers $(\mathrm{d}=0.52)$.

Table 7

Descriptive Statistics of the Relationships among the Three Groups of Participants

\begin{tabular}{lrrrrr}
\hline & Receive & Respond & \multicolumn{1}{l}{ Value } & Organise & Internalise \\
\hline Students & 0.482 & 0.199 & 0.195 & 0.057 & 0.035 \\
Teachers & 0.270 & 0.152 & 0.396 & 0.170 & 0.019 \\
Researchers & 0.342 & 0.231 & 0.184 & 0.164 & 0.081 \\
f value & 930.196 & 390.540 & 683.526 & 337.001 & 80.160 \\
p value & 0.000 & 0.000 & 0.000 & 0.000 & 0.000 \\
\hline
\end{tabular}

Table 8

Effect Sizes of Relationships Among the Three Groups for the Five Affective Levels

\begin{tabular}{lll}
\hline & Teachers & Researchers \\
\hline Receive & & 0.29 \\
Students & $0.43^{\text {a }}$ & 0.15 \\
Teachers & - & - \\
Researchers & - & \\
Respond & & 0.08 \\
Students & 0.12 & 0.20 \\
Teachers & - & - \\
Researchers & - & \\
Value & & 0.03 \\
Students & $0.50^{\text {a }}$ & $0.52^{\text {a }}$ \\
Teachers & - & - \\
Researchers & - & Continued on next page
\end{tabular}

Continued on next page 
Table 8 - continued from previous page

\begin{tabular}{lll}
\hline & Teachers & Researchers \\
\hline Organise & & \\
Students & 0.26 & 0.24 \\
Teachers & - & 0.02 \\
Researchers & - & - \\
Internalise & & \\
Students & 0.08 & 0.23 \\
Teachers & - & 0.31 \\
Researchers & - & - \\
\hline
\end{tabular}

${ }^{a}$ Medium to large effect (practical significance)

\section{Discussion of Results of the Affective Learning Experiences of the Project Participants}

The analyses indicated that the three groups of project participants were all subjected to affective learning experiences. The discussion of the results therefore related to the three groups of project participants.

\subsection{Affective Learning Experiences of Students}

Derived from the results in Table 7, the students participating in the project presented the highest mean $(0.482)$ for receive which implies that they were open to play the UFractions game and ActiveMath, communicated with the other participants, engaged with the learning content, and explored while playing the UFractions game and ActiveMath. Respond (0.199) and value (0.195) offered similar results, which suggest that the students were involved with the activity, responded through their reflections in the How-Am-I-Feeling-blog and learning diary, and committed to finishing the UFractions game and ActiveMath tests. Organise (0.057) and internalise $(0.035)$ had the lowest results. This indicates that they did not really make comparisons, execute modifications, solve complex problems or adopt a specific view of mathematics. However, the overall results indicate that the students experienced learning-centred emotions while playing the UFractions game. This is an indication that the researchers intelligently integrated the technology with the design of the UFractions game and the ActiveMath tests.

\subsection{Affective Learning Experiences of Teachers}

Table 7 indicates that teachers, in comparison with students, achieved a higher mean (0.396) for value and less for receive (0.270). Even though the teachers participating in the project were open to experiences, attentive to the environment, and prepared to listen to others, they primarily adopted the role of an educator who reflects, challenges, 
criticises, persuades, commits to certain goals, and expresses opinions. The teachers responded $(0.152)$ and they organised $(0.170)$ by adjusting the subject content to the appropriate level. However, the teachers who participated in the project seldom internalised (0.019) while they solved complex problems, nor adopted a specific worldview, nor influenced others to adopt their philosophy.

\subsection{Affective Learning Experiences of Researchers}

The researchers achieved the highest mean for receive $(0.342)$. The learning diary, the blog, the experimental notes, and the interviews with the students and the teachers during the project created an opportunity for the researchers to be aware of and attentive to the environment. The researchers listened to the opinions of the participants in order to adjust the subject content of the UFractions game and the ActiveMath tests for students to engage in affective learning emotions. The researchers responded (0.231) by interpreting the suggestions of the teachers and students as well as including the written reflections. Even though the researchers organised (0.164) to a lesser extent, the first researcher modified the subject content of the UFractions game based on her interaction with the other participants in the project. Value $(0.081)$ obtained the lowest results, which indicates that the first researcher did not intend to adopt a worldview or philosophy.

The teachers and researchers observed the students' interactions. The students listened, asked for advice, posed questions to the teachers and researchers, focused on their learning, interacted with the mobile game, discussed their learning with their peers, and shared their feelings with the researchers and on the blog. The students were younger than the teachers and researchers and therefore their value systems were less mature than those of the teachers and researchers. Through their learning behaviour, their commitment to play and complete the game, and their responses to the researchers in the blogs contributed towards the value of the affective learning. The students' role was crucial during the introduction and the adaption of the new mathematics concepts. Fractions are difficult concepts frequently taught with stereotypical representations. Through the compilation of the UFractions mobile game, the designers triggered students' mathematical thinking during play of the fantasy stories game (Kafai, 1995). The INBECOM project intervention enabled students to learn about fractions in a playful manner. The teachers, as well as researchers, were more familiar with manipulation of fractions due to their extensive experience with fractions, as well as their diverse roles as teachers and researchers in the project. The teachers participated mostly in mobile game development and experiments, and to a lesser extent in evaluation and theory generation.

The participants from the three groups who contributed in the experiments and the teaching and learning sessions were open to new experiences, willing to listen and to experience emotions; they became aware of what the project offered, but rarely contributed ideas and posed questions that related to the new model for technology-enhanced learning intervention in schools. The participants' affective learning inclined more towards the level of receive than the level of value $(d=0.53$, medium effect $)$; and more towards 
the level of receive than the level of organise $(d=0.76$, medium effect) (Table 6). There were also practically significant differences between the levels of receive and internalise $(d=0.92)$. This confirms that the participants' affective learning occurred mostly on receive level. From Table 4, it becomes clear that the participants received more than they responded, valued, organised or internalised. For the probability level of $p=0.00$, we conclude that there were significant differences between the variances of the differences (Table 4). This result is in line with what we expected since learning in all domains firstly happens at the least complex process level, and without interaction on this level, no learning can occur. Interestingly, there were no similar significant effects between other levels of affective learning.

\section{Conclusions and Future Research}

The underpinning questions for this project evaluation according to Krathwohl's affective criteria were twofold. In the first place, we explored the affective learning experiences of three groups of participants (teachers, students and researchers) on the use of mobile game enhanced learning on fractions in mathematics. The adoption of the affective learning domain levels (Krathwohl, et al., 1964) encouraged the research participants to not only receive information, but actively participate in the learning process; to respond to what they learned; to associate value to the acquired knowledge; to organise the values; to elaborate on their learning; to build abstract knowledge; and to adopt a belief system and a personal worldview. The researchers were interested in the other research participants' motivation and attitudes toward mathematics and technology-enhanced learning and accordingly identified effective, encouraging and motivational experiences of all the participants in the project. It is therefore important that the affective domain is taken into account while designing education during the use of technology enhanced learning.

Teachers' knowledge of using educational technologies should be increased so that they know what learning dimensions and domains different materials supports in order to achieve deep learning outcomes also in the affective domain of learning.

Through a process of quantitizing of the qualitative data collected from the 311 data sources, statistical tests indicated a series of results which addressed the second research question. The researchers determined the significance of the relationships among the affective learning experiences of the three groups of participants (students, teachers and researchers) in the INBECOM project. Affirmation of affective learning at all five levels occurred among the three groups of participants. The results show that the affective learning mostly took place on the receive level, indicating that the participants received more than they responded, valued, organised or internalised. There was also a significant effect of research participants pertaining to receive; students' affective learning occurred more on receive level than that of the teachers; and teachers' affective learning emerged more on the value level.

The importance of the affective domain in education is widely acknowledged and there are many theoretical and empirical variables to define and measure in order to 
scale affective learning (McCoach, Gable, \& Madura, 2013). Instructional-design theories have addressed the affective domain (Martin \& Reigeluth, 2013). Despite this, comparing the results of this study with current research was demanding since there are few studies that refer to affective learning and technology-enhanced learning. Rovai, Wighting, Baker, and Grooms (2008) developed and validated a self-report instrument, named CAP Perceived Learning Scale for measuring learning in the cognitive, affective, and psychomotor domains in the use of technology at higher education-level. However, the CAP Perceived Learning Scale does not measure learning at all five levels of Krathwohl's affective criteria, but considers nine questions relating to students' attitudes. Rowell (2015) measured the affective learning dimension of Open Educational Resources (OER) using three items included in the OER perceptions survey. According to this study, students have a greater sense of self-reliance as a result of their enrolment in a course that employed OER compared to a course that did not. Relating to the affective learning of mathematics, Lim and Chapman (2015) identify priority affective variables within and across the three affective variables of (i) motivation, (ii) attitudes, and (ii) anxiety - the key sub-constructs that educators should focus on while engaging with technology-enhanced learning strategies. Kiili and Ketamo (2017) investigated the use of a digital game-based mathematics test with respect to affective learning and noted that game-based assessment could lessen test anxiety as well as increase school satisfaction.

Our study raised a number of issues that could be addressed in the future. Examples are: (i) how affective levels of learning are intertwined with cognitive levels of learning while learning mathematics in a technology-enhanced learning environment; (ii) how pedagogical models which take into account both cognitive and affective aspects of learning support deep learning; (iii) how motivation for learning relates to the different levels of affective learning; (iv) how affective learning concepts could be integrated into mathematics technology-enhanced learning classrooms; and (v) how to examine teachers' affective learning while they integrate new pedagogical skills in their teaching and learning.

The researchers believe that the use of the Krathwohl's framework provided novel and valuable insights to project evaluation methodology, and also contributed towards the planning and conducting of technology-enhanced learning projects. We have indicated that the affective domain of learning provided insight into the learning and research outcomes of the INBECOM project.

\section{Limitations of the Study}

Limitations of the study relate to two aspects: (i) We involved only the two technological tools of UFractions mobile game and ActiveMath intelligent tutoring system. Other games were not considered and tutoring systems were excluded. (ii) Although the study took place over a multitude of years from 2007-2014, it made use of a snapshot evaluation; a longitudinal analysis could have provided deeper insights into the issues of accommodation and adaptive affective learning of mathematics. 


\section{References}

Adkins, S. (2004). Beneath the tip of the iceberg. American Society for Training \& Development,, 58(2), 28-33.

Admiraal, W., Louws, M., Lockhorst, D., Paas, T., Buynsters, M., Cviko, A., Janssen, C., De Jonge, M., Nouwens, S., Post, L., Van der Ven, F., \& Kester, L. (2017). Teachers in school-based technology innovations: A typology of their beliefs on teaching and technology. Computers \& Education, 114, 57-68.

Alessi, S. M., \& Trollip, S. R. (2001). Multimedia for Learning: Methods and Development (3rd ed.). Boston: Allyn \& Bacon.

Anderson, L. W., Krathwohl, D. R., \& Bloom, B. S. (2001). A taxonomy for learning, teaching, and assessing: a revision of Bloom's taxonomy of educational objectives: Longman.

Baker, R. S. J. d., D’Mello, S. K., Rodrigo, M. M. T., \& Graesser, A. C. (2010). Better to be frustrated than bored: The incidence, persistence, and impact of learners' cognitive-affective states during interactions with three different computer-based learning environments. International Journal of Human-Computer Studies, 68(4), 223-241.

Barzilai, S., \& Blau, I. (2014). Scaffolding game-based learning: Impact on learning achievements, perceived learning, and game experiences. Computers \& Education, 70, 65-79.

Bloom, B. S. (1956). Taxonomy of Educational Objectives, Handbook I: The Cognitive Domain. New York: David McKay Co Inc. .

Boeije, H. (2002). A purposeful approach to the constant comparative method in the analysis of qualitative interviews. Quantity and Quality, 36, 391-409.

Bolin, A. U., Khramtsova, I., \& Saarnio, D. (2005). Using Student Journals to Stimulate Authentic Learning: Balancing Bloom's Cognitive and Affective Domains. Teaching of Psychology, 32(3), 154-159.

Calvo, R. A., \& D’Mello, S. K. (2011). Explorations In the Learning Sciences, Instructional Systems and Performance Technologies: New Perspectives on Affect and Learning Technologies: Springer New York.

Chapman, J. W. (1988). Learning disabled children's self-concepts. Review of Educational Research, 58(3), 347-371.

Cramer, D., \& Howitt, D. (2004). The SAGE dictionary of statistics. Thousand Oaks, CA: SAGE.

Cronje, J. (2006). Paradigms regained: toward integrating objectivism and constructivism in instructional design and the learning Sciences. Educational Technology Research and Development, 54(4), 387-416.

D’Mello, S., \& Graesser, A. (2011). Dynamics of affective states during complex learning. Learning and Instruction, 22(2), 145-157.

Domingo, M., \& Garganté, A. B. (2016). Exploring the use of educational technology in primary education: Teachers' perception of mobile technology learning impacts and applications' use in the classroom. Computers in Human Behavior, 56, 21-28.

Duncan-Hewitt, W., Leise, C., \& Hall, A. (2005). Affective Domain. Faculty Guidebook.

Elander, K., \& Cronje, J. C. (2016). Paradigms revisited: a quantitative investigation into a model to integrate objectivism and constructivism in instructional design. Educational Technology Research and Development, 64(3).

Griffith, G. G., \& Nguyen, A. D. (2006). Are Educators Prepared to Affect the Affective Domain? National Forum of Teacher Education Journal, 16(3).

Grootenboer, P., \& Marshman, M. (2016). Mathematics, affect and learning. Sunshine Coast, Australia: Springer.

Hamari, J., Shernoff, D., Rowe, E., \& Coller, B. (2016). Challenging games help students learn: An empirical study on engagement, flow and immersion in game-based learning. Computers in Human Behavior, 54, $170-179$.

Hannula, M., Bofah, E., Tuohilampi, L., \& Metsämuuronen, J. (2014). A longitudinal analysis of the relationship between mathematics-related affect and achievement in Finland

Hannula, M. S., Bofah, E., Tuohilampi, L., \& Metsämuuronen, J. (2014). A longitudinal analysis of the relationship between mathematics-related affect and achievement in Finland. In S. Oesterle, P. Liljedahl, C. Nicol \& D. Allan (Eds.), 38th conference of the IGPME and the 36th conference of the PME-NA (Vol. 3, pp. 249-256). Vancouver, Canada: PME.

Hannula, M. S. (2002). Attitude towards mathematics: emotions, expectations and values. Educational Studies in Mathematics, 49(1), 25-46.

Hannula, M. S. (2006). Motivation in mathematics: Goals reflected in emotions. Educational Studies in Mathematics, 63(2), 165-178. 
Ignacio, N. G., Nieto, L. J. B., \& Barona, E. s. G. (2006). The affective domain in mathematics learning. International Electronic Journal of Mathematics Education, 1(1), 16-32.

Kafai, Y. B. (1995). Mind in Play: Computer game design as a context for children's learning. Hillsdale, NJ: Lawrence Erlbaum Associate Inc. Publishers.

Kiili, K., \& Ketamo, H. (2017). Evaluating Cognitive and Affective Outcomes of a Digital Game-Based Math Test. IEEE Transactions on Learning Technologies, PP(99), 1-10.

Kiili, K., \& Perttula, P. T. A. (2012). Exerbating for schools: Combining body and brain training. Procedia Computer Science, 15(2012), 163-167.

Krathwohl, D., Bloom, B., \& Masia, B. (1964). Taxonomy of Educational Objectives. Handbook II: Affective domain New York: David McKay.

Laine, T. H., \& Nygren, E. (2014). Creating Technically Balanced and Motivating Mobile Learning Games. In J. Traxler (Ed.), Accepted to be published in the book Mobile Learning: Next Generation. New York: Routledge.

Laine, T. H., Nygren, E., Sutinen, E., Islas Sedano, C., Joy, M. S., \& Blignaut, S. (2011). Ubiquitous mathematics from South Africa to Finland: Does reverse transfer work? In I. Chen \& T. Kidd (Eds.), Ubiquitous Learning: Strategies for Pedagogy, Course Design and Technology. (pp. 249-282). Charlotte, NC: Information Age Publishing

Leech, N., \& Onwuegbuzie, A. J. (2007). A typology of mixed methods research design. Springer Science and Business media, 43, 265-275.

Lehman, B., D’Mello, S., \& Graesser, A. (2012). Confusion and complex learning during interactions with computer learning environments. The Internet and Higher Education, 15(3), 184-194.

Lim, S., \& Chapman, E. (2015). Identifying affective domains that correlate and predict mathematics performance in high-performing students in Singapore. Educational Psychology, 35(6), 747-764.

Littledyke, M. (2008). Science education for environmental awareness: approaches to integrating cognitive and affective domains. Environmental Education Research, 14(1), 1-17.

Martin, B. L., \& Reigeluth, C. M. (2013). Affective education and the affective domain: Implications for instructional-design theories and models. In C. M. Reigeluth (Ed.), Instructional-design theories and models: A new paradigm of Instructional heory (Vol. 2, pp. 485-509). New York: Routledge.

McCoach, D. B., Gable, R. K., \& Madura, J. P. (2013). Affective characteristics in school and corporate environments: Their conceptual definitions. In D. B. McCoach, R. K. Gable \& J. P. Madura (Eds.), Instrument Development in the Affective Domain. New York: Springer.

McLeod, D. B. (1992). Research on affect in mathematics education: A reconceptualization. Handbook of research on mathematics teaching and learning, 575-596.

McLeod, D. B., Metzger, W., \& Craviotto, C. (1989). Comparing experts' and mathematics novices' affective reactions to mathematical problem solving: An exploratory study. In G. Vergnaud (Ed.), Proceedings of the Annual Conference of the International Group for the Psychology of Mathematics Education (Vol. 2, pp. 296-303). Paris, France: PME.

McMillan, J. H., \& Schumacher, S. (2001). Research in education: A conceptual introduction (5th ed.). Virginia: Addison Wesley Longman.

Nabors, W. K. (2003). From fractions to proportional reasoning: a cognitive schemes of operation approach. Journal of Mathematical Behavior, 22, 133-179.

Nacke, L. E., \& Deterding, S. (2017). The maturing of gamification research. Computers in Human Behavior, $71,450-454$.

Nwana, H. S. (1990). Intelligent Tutoring Systems: an overview. Artificial Intelligence Review, 4, $251-277$.

Nygren, E., Blignaut, S., Els, C., Laine, T. H., \& Sutinen, E. (2009). Story-based UFractions Mobile Game in South Africa: Contextualization Process and Multidimensional Playing Experiences. In 2nd International Workshop on Story-Telling and Educational Games (STEG'09). Aachen, Germany.

Nygren, E., Sutinen, E., Blignaut, A. S., Laine, T. H., \& Els, C. J. (2012). Motivations for Play in the UFractions Mobile Game in Three Countries. In (pp. 30-48): IGI Global.

Özyurt, Ö., Özyurt, H., Baki, A., \& Güvenb, B. (2013). Integration into mathematics classrooms of an adaptive and intelligent individualized e-learning environment: Implementation and evaluation of UZWEBMAT. Computers in Human Behavior, 29 726-738.

Qian, M., \& Clark, K. (2016). Game-based Learning and 21st century skills: A review of recent research. Computers in Human Behavior, 63, 50-58.

Ramma, Y., Bholoa, A., Watts, D., \& Samy, M. (2017). A paradigm shift in the teaching and learning of science using technology in Mauritius: Making a case for incorporating the affective domain. In Taylor \& Francis Open: Taylor and Francis. 
Reigeluth, C. M. (1999). Instructional-design theories and models: A new paradigm of instructional theory. In (Vol. 2, pp. 690). Abingdon, OX: Lawrence Erlboum Associates.

Remer, D. S., \& Nieto, A. P. (1995). A compendium and comparison of 25 project evaluation techniques. Part 1: Net present value and rate of return methods. International Journal of Production Economics, 42(1995), 70-96.

Reyes, L. H. (1984). Affective variables and mathematics education. The Elementary School Journal, 84(5), $558-581$.

Rieber, L. P. (2001). Designing learning environments that excite serious play. In annual meeting of the Australasian Society for Computers in Learning in Tertiary Education. Melbourne, Australia.

Rovai, A., Wighting, M., Baker, J., \& Grooms, L. (2008). Development of an instrument to measure perceived cognitive, affective, and psychomotor learning in traditional and virtual classroom higher education settings. The Internet and Higher Education, 12(1), 7-13.

Rowell, J. (2015). Student perceptions: Teaching and learning with open educational resources. Retrieved from ProQuest Dissertations (3727487). Accessed on 2017, 2 February 2018. https://dc.etsu.edu/cgi/viewcontent.cgi article $=3925 \&$ context $=$ etd

Ruffell, M., Mason, J., \& Allen, B. (1998). Studying attitude to mathematics. Educational Studies in Mathematics, 35(1), 1-18.

Saldaña, J. (2009). The coding manual for qualitative researcher. Thousand Oaks, CA: SAGE.

Tondeur, J., Van Braak, J., Ertmer, P., \& Ottenbreit-Leftwich, A. (2016). Understanding the relationship between teachers' pedagogical beliefs and technology use in education: A systematic review of qualitative evidence. Educational Technology Research and Development, 65, 555-575.

Tsovaltzi, D., McLaren, B. M., Melis, E., Meyer, A.-K., Dietrich, M., \& Goguadze, G. (2010). Learning from erroneous examples. In Intelligent Tutoring Systems (pp. 420-422): Springer.

Turtiainen, E., Blignaut, S., Els, C., Laine, T. H., \& Sutinen, E. (2009). Story-based UFractions Mobile Game in South Africa: Contextualization Process and Multidimensional Playing Experiences. In Proceedings of the Second Workshop of Story Telling and Educational Games.

Verner, I. M., Aroshas, S., \& Berman, A. (2008). Integrating supplementary application-based tutorials in the multivariable calculus course. International Journal of Mathematical Education in Science \& Technology, 39(4), 427-442.

Volk, M., Cotic, M., Zajc, M., \& Starcic, A. I. (2017). Tablet-based cross-curricular maths vs. traditional maths classroom practice for higher-order learning outcomes. Computers \& Education, 114, 1-23. 
E.Nygren is a PhD student in Computer Science at the University of Turku, Finland. Her research in education technology focuses mainly on diverse dimensions of learning Mathematics by technology. Nygren is working as a principle in the Evangelical Folk High School of Kitee, Finland.

A.S. Blignaut research focuses on innovative teaching and learning with technology, interaction in virtual learning communities, ICT for Development, ICT for Open Distance Education, and eyetracking evaluation of serious games. Seugnet's research reflects numerous national and international research outcomes that include articles in accredited journals, book chapters, conference papers, as well as the supervision of various masters' dissertations and doctoral theses on national and international level.

V. Leenderz is the head of North-West University's Technology Enhanced Learning and Innovative Education and Training in South Africa (TELIT-SA). Prof. Leenderz's research interests include research on the theory and practice of learning technologies, and she has for example developed guidelines for the professional development of mathematics teachers to integrate technology in their reaching and learning practices. She conducts research to inform innovative teaching and learning with technology through interdisciplinary collaboration.

E. Sutinen is full professor of Computer Science (Interaction Design) at the University of Turku, Finland. He is also the founder of the EdTech research group at the University of Eastern Finland. He is a specialist in the field of educational technology and ICT for development. Prof. Sutinen's research interests include technologies for special education, contextualized IT education, visual and textual tools for learning, and natural language processing methods for business intelligence and for emotion detection. For these, he supervises and collaborates with several $\mathrm{PhD}$ students and educational institutions. 